\title{
Group Analysis: Other Sights of the Conscious and the Unconscious
}

\author{
Abreu-Afonso José, Dinis César, Ferreira Guilherme, Sara Maria Caseiro Ferro, Marques Paulo Motta, \\ Melo João Carlos, Neto Isaura, Porto Manuela, Rodrigues Teresa Bastos, Valente Aucíndio \\ Portuguese Group Analytic Society and Group Analytic Psychotherapy (SPG PAG), Lisbon, Portugal
}

\begin{abstract}
The authors aim at introducing group analysis as a theory and a practice as it is conceptualized by the Portuguese Group Analytic Society and Group Analytic Psychotherapy (SPG PAG, Lisbon). In order to reach this objective, the authors, senior members of the SPG PAG, will present the group analytic main concepts: matrix, pattern, transference, counter-transference, communication-levels, working-through, mirroring, resonance, free floating discussion, and anti-group.
\end{abstract}

Keywords: pattern, matrix, communication-levels, free floating discussion, mirroring, anti-group

\section{Definition of Group Analysis}

Group-analysis came into view with Foulkes' works in the Northfield Hospital in London by the 1940s during the World War II. His conceptions among us were modified by Cortesão (1989). To speak about group-analysis in Portugal, it is indispensable to define its specificity and to clarify the concepts which support it. Thus, it is conceptualized and described as a way of investigation and therapy based on the psychoanalytic theory; however, it operates with discriminated proceedings, which are in connexion with the new setting, the group, and with the theory and technique of the group-analysis. The purpose of the group-analysis is working through a made steady transference structure, which allows its distinction from the group-psychotherapy based on the psychoanalytic theory.

Cortesão (1989) defines group analytic process as "the way through which several theoretical and practical dimensions - which contribute to the consistency and shape of the group analytic therapy-are framed, organized and perform a function".

Once the specific concepts are structured and organized, they cross one another to perform the practice. The therapeutic process is performed during the intercourse between the group matrix and the groupanalitic pattern.

The pattern is gradually integrated into the dynamic matrix as Ancona (1992) says. We can consider that

\footnotetext{
Abreu-Afonso José, Ph.D., psychoanalist, SPG PAG, the Group Analytic Society International (GASi).

Dinis César, M.D., psychiatrist, SPG PAG, the Group Analytic Society International (GASi).

Ferreira Guilherme, M.D., psychiatrist, SPG PAG, the Group Analytic Society International (GASi).

Sara Maria Caseiro Ferro, M.D., psychiatrist, SPG PAG, the Group Analytic Society International (GASi).

Marques Paulo Motta, Ph.D. student, SPG PAG, the Group Analytic Society International (GASi).

Melo João Carlos, M.D., psychiatrist, SPG PAG, the Group Analytic Society International (GASi).

Neto Isaura, M.D., psychiatrist, psychoanalyst, SPG PAG, the Group Analytic Society International (GASi).

Porto Manuela, M.S., SPG PAG.

Rodrigues Teresa Bastos, M.S., SPG PAG, the Group Analytic Society International (GASi).

Valente Aucíndio, M.D., psychiatrist, SPG PAG.
} 
there is an exogenous pattern, which depends on the groupanalyst's personality including his character, family matrix and cultural aspects that function as a seed or catalyser. There is also an endogenous pattern, which self endogenous by the matrix under the action of the exogenous pattern.

\section{Matrix}

Foulkes (1962) defined matrix as: "the hypothetical communication net and relationship in a given group. It is the set shared stage that ultimately determines the meaning and significance of all events, and which integrates all communications and interpretations, verbal and nonverbal".

Later, Cortesão (1989) defined group analytic matrix as: "is the specific network of communication, relation and elaboration, which, by integrating the group analytic pattern, fosters the evolution of group-analytic process inside the underpinning theoretical and technical dimensions".

As inferred, it is a dynamic process that simultaneously results and conditions the interactions and interrelationships among its various elements, which can lead to the formation and modification of IRM (the internal relational matrix) of each one.

However, for a better understanding of the importance of the group and group-analytic matrix in the therapeutic process just remember that since we are born, until we die, we almost always live within a group. Be the family group, the school group, the friends group, the sports group, the professional group, or any other else, and that any one of these groups has a specific matrix that influences whoever is into it.

We also easily accept that from all these groups, the most important is the family, as it is our first group and who has more influence in our development process, either motor or psycho-emotional, as a consequence of the existing familiar matrix.

We understand development process as the acquisition of structures and dynamic ways of thinking, feeling, and relate with one another, in which are embedded defence mechanisms, conflicts, desires, fears, whether conscious or unconscious to us. It is with this fundamentally acquired form of relating, named as IRM (which may be more or less appropriate or inappropriate to the environment we live in), that we will act in the group, i.e., in its relationship dynamics, communication and development that constitute its group matrix and where the group analyzed, through a process of regression, transfer and consequent group analytic interpretations, triggers his process of group analytic transformation.

So, succinctly we may say that the group analysis has the task of recreating these people (pretention aside), but now in a more suitable, harmonious and not suffering generator (this is normal), with the creation/generation of a new way to communicate and to relate through the group analytic matrix that the group is capable of developing in the group analytic therapeutic process.

\section{Pattern}

The concept of pattern was contextualized by Cortesão (1989) who widely reasoned about the semantic source and the ambiguity of the meaning of the word pattern in order to clarify the meaning used by him. The conception of pattern produced a controversy with Foulkes because a wrong sense was ascribed to the signification imprinted by Foulkes.

Pattern is explained by Cortesão (1989) as "is the specific kind of posture that the group analyst conveys and endures into the groupanalytic matrix in order to interpret what promotes and develops the group analytic process". 
When speaking about pattern, we are relating to conjoined characteristics and competences performed by the group analyst that will function as a catalyst which allows the accommodation and the development of the therapy.

Theoretically, it comprises three vertexes: nature, function, and purpose.

(1) Nature - it means the characteristics of the group analyst:

(a) as a persona-personality, character, representation of the internalized familiar and socio-cultural matrixes, analytic training (that is to say how he internalized and identified himself with his analyst), empathising ability to be in group and to foment authentic relationships based on truth and honesty;

(b) as a conveyor-his ability in connexion with his professional formation level such as; group analyse formation course, supervision and both contemporary and scientific knowledge.

(2) Function - it is related to the settlement of rules and postures:

(a) Rules: i. to select patients in order to facilitate the development of the group process; ii. to establish a therapeutic agreement demanding seal and forbidding the patients to have any kind of relationship among them outside the therapeutic context, and forbidding the therapist to keep any relationship with the patients' family, as well; iii. to guarantee a space for the therapeutic sessions and also guarantee that both punctuality and frequency to the sessions will be observed by the group analyst: to privilege the spoken intercourse and do not allow the acting out and secondary profits; and to propitiate a floating discussion;

(b) Postures: i. the group analyst's interventions will be of clarification, confrontations and reformative; ii. interventions will be formal and he won't speak about himself; iii. interpretations go from a genetic level to the transference level and commutative level; and iv. will be attentive to the binomial phenomenon of the transference/countertransference in order to promote an emphatic relation, which will value the treatment.

(3) Purpose - to fit the induction and the maintenance (in the groupanalytic matrix) of the group analytic process through the promotion of:

(a) rational and emotional insights;

(b) interventions which produce alterations of the self;

(c) development of the discriminate structures and the working of the self, which will allow a relative autonomy and a consistent and normal dependence.

\section{Transference}

Psychoanalysis considers transference as an essencial part of the therapeutic process: a process that results from the actualization of the displacement of unconscious impulses and desires into specific current objects and relationships. It is a repetition of child relational prototypes felt with a vivid sense of reality (Laplanche $\&$ Pontalis, 1967). A process... "by which he relates to his analyst as though he was some former object in his life; by which he projects on to his analyst object-representations acquired by earlier introjections", "by which he endows the analyst with the significance of another, usually prior, object" (Rycroft, 1968).

We may consider that transference phenomena occur frequently in most life relationships, beyond the psychoanalytic relationship. These phenomena are prone to occur ever since we face hierarquical relationships, either when the object is invested as a powerful one (teacher-pupil, police-driver, etc.) or when the object may provide basic necessities to the subject, such as doctors, nurses, priests, etc..

The continuity that characterizes the psychoanalytic relationship conveys the process so-called 
transference neurosis, a fresh and current repetition of the child neurosis towards the object-analyst. This way we may accede to the pathological primary object relationships.

The most important aspect to be defined for group analysis is the legitimacy of the use of the concept "transference neurosis" and its resolution within the group analytic process. This problem was considered as a controversial one and it was discussed in the first. European Symposium in Group Analysis held in Portugal (Estoril) in 1969. Since then it has become a nucleus of controversy between the English group analytic society headed by Foulkes and the Portuguese Society headed by Cortesão.

In spite of the fact that Foulkes changed his mind on this matter several times, he wrote in 1975: "transference neurosis in the group... contains the key... of the patient's neurosis in the same way as it occurs in the dyadic psychoanalytic relationship" (Foulkes, 1975).

Cortesão (1989) definitely thought that "transference neurosis - in spite of being defined in a different setting - exists in a significative and natural way in this new setting - the group.... It's different in its form and structure, but it is not that different in its contents and function. It's different but not contradictory" (Cortesão, 1989).

The way the transference neurosis is conceptualized and operationalized in a group setting has been developed by the Portuguese group analysts. According to this, we highlight Maria Rita Mendes Leal's concept (Leal, 1970): "internal interpersonal matrix" or "personal group matrix", which means that every individual has in his/her mind the whole primary object representations, according to the nuclear family. This complex and dynamic net becomes more and more complex through the relational groups where each individual will be part of during life. It's a kind of "Individual Brandt", for the best and for the worse.

The group analytic group will provide a favoured setting, activated by regression, where the "personal group matrix" of each group member may occur in a clear way. This way, each individual transference neurosis becomes better understandable in its whole structure. The group analyst is the target object of the transference relationship. Therefore, the group analyst will be felt differently by every member of the group. This way the group analyst must also deal with each of the members in a different and discriminated way, never forgetting the empathic equilibrium towards them all. Sibling conflicts are powerfully updated within a group, as well those connected to the Edipus complex. It's frequent that the group and the group analyst are the other two vertices of the edipal triangle. Lateral transferences are always present either they are considered strict osenso, or as a result of displacements of the transference towards the group analyst.

Nowadays we consider, in general, that transference and counter transference are an interactive binomial, influencing each other in a reciprocal way. However, this is an asymmetrical situation, as it is the care giver-child relationship. Therefore, the scrutiny and evaluation of his/her empathic capacity towards each member is extremely important from the beginning while selecting a new member.

Lastly, we would like to remind Daniel Stern's concept of "moments of meeting" (Stern et al., 1998). These may be or not mediated by an interpretation. What's more important is that they result from a common construction, authentic and specific for each member of the dyadic psychoanalytic relationship. Both must recognize the deep affective and rational qualities of those moments of the analytic process.

In a group analytic group, there are more members who can also participate in the construction of such moments through their own authenticity, performing moments of multiple genuine reciprocal empathy leading to the so-called "empathic resonance box" (Dinis, 2001), which is definitely a major therapeutic tool. 


\section{Countertransference}

As in psychoanalysis, countertransference in group is not only a problematic topic, but also a communication tool serving the therapeutic process. There are many variations in its definition (Laplanche \& Pontalis, 1967), including all that, in the analyst personality, interferes in the process, or only the analyst's unconscious reactions caused by patient's transference. In this last definition-reaction to other's transference, we must not forget that the same will happen with the analysand.

It is generally accepted that the analyst's feelings provide important clues to what is going on in the group. As noted by Hopper (2006), Foulkes was the first group analyst recognizing that therapist is both object and subject of emotionally corrective transmuting internalization. He considers the countertransference processes in the group in terms of resonance and mirroring more than in the classical terms of group analyst's psychopathology. He preferred to call resonance to the analyst's inner conscious reflections, instead of using the term countertransference (Foulkes, 1977).

Kadis, Krasner, Winick, and Foulkes (1963) stress that countertransference in group is more complex and more visible than in individual therapy. The group analyst has simultaneously to interact with different people. Their reaction in group will differ from the individual situation. Moreover, even knowing well a patient individually, when in group, unexpected aspects to the clinician emerge.

The analyst's countertransference then responds to various forms of group transference from members, and various collective phenomena such as the group as a whole, subgroups, antigroup (Hopper, 2006). In group analysis, the analyst is much more exposed than in psychoanalysis, to behavior, countertransference and the scrutiny from analysands (Cortesão, 1989). Countertransference is also very complex by the multiplicity of viewpoints in a group, which can lead to thought and affection dissociation in the therapist. The group is basically always schizoid and when in regression and archaic anxieties, naturally stimulates schizoparanoid mechanisms. Therefore, it is natural that neurotic and psychotic countertransference phenomena arise. We must understand the current and regressive vicissitudes of group transference and work through neurotic and psychotic countertransference.

In a group, everything gets new proportions to the analyst whose emotions are the response to the emotions transferred by the group, not only by words, but by voices intonation, physical proximity, mimicry, postures, glances, silences, smells, and breathing rhythms, which are many (Rouchy, 1982). Mello Filho (1986) stresses that the group, also, has the perception of analyst's feelings through non-verbal communication (voice, posture, vasomotricity). It is true that the analyst also emanates, intentionally or unintentionally, evidence to which patients give meanings. The great importance of the somatic in groups draws attention to the meaning of the body to others, reinforces projective identification, and promotes the emotion transference by means of communication very close to the primitive regressive forms of objectal relationship in the transitional space or even before the objectal relationship (Rouchy, 1982).

On the other hand, the analyst is tested face to face, target of aggression and attacks of analysands. Jealousy, envy, and rivalry can increase in group experience, among analysands or directed to the therapist. A regressive atmosphere in sessions favors these situations. The plurality of participants and interaction makes easier to the analyst to be touched by projective identifications, unable to find the source of frustration, anger or rejection that sometimes he feels. This can lead to feelings of guilt, low professional self-esteem, increasing aggressiveness or even lead to the withdrawal of working with groups. It becomes more complicated in 
situations when the analyst, by his omnipotence, does not recognize that these affections are part of the process and that some patients can only progress from our mistakes. If the therapist does not recognize his feelings, he may be falling in the indoctrination of the group infantilizing it (Mello Filho, 1986).

When speaking about countertransference, it can also be a reference to an unresolved difficulty of the analyst. Besides the danger of favoring a group member and rejecting another, there is the risk of unconsciously use a patient to fill unmet needs. A group can be an immense weight but also a great source of pleasure-The group cannot be a source of satisfaction of the analyst's childhood deprivations, the group cannot be an audience to express and gratify narcissistic or other needs (Blay Neto, 1966, as cited in Kutter, 1976).

Ormont $(1970 ; 1991)$ reported by Hopper (2006) suggests that the group analysts should use the group as an aid in resolving the subjective countertransference (in the pathological countertransference sense), as they should use objective countertransference to resolve group resistances. This oversight function of the group is one of the most interesting aspects of working in this setting, and promotes the ongoing investigation of transference and countertransference.

Zimerman (2005) refers to "countertransference effect" on the selection for the groups, distinguishing two aspects: on one hand what the patient raises in the analyst, on the other what the analyst thinks of that person's interaction with other participants. Neto (2003) and Dinis (1994) both advocate the homogeneity in countertransference, to avoid imbalances in the group. We agree with these authors. The group-analytic setting itself is complex enough - from our point of view, especially by countertransference issues. Analysands must be in an equivalent position to the analyst at the staring point of their processes.

Foulkes (1977) wrote about the possibility of openly analyzing the transference in group, but recommended it should not become a routine. Such an interpretation may be useful at times when one realizes communication resistance located on him, evolving him, if not being caused by him. But not all the way patients deal with mental pain. Each analyst's intervention, however correct and appropriate is not heard/felt equally by all group members. This question gains special importance in the interpretations involving countertransference.

\section{Communication Levels}

In group analysis or group analytic psychotherapy, communication is obviously the central element that enables the whole analytical process to occur within the theoretical and technical conditions inherent to this objective. Several authors have specifically analysed this aspect but in this short communication we wish to deal with the idea of conceptualization by Eduardo Cortesão (1989), the introducer of group analysis in Portugal, in what concerns the levels of experience and interpretation in the context of group analysis and group analytic psychotherapy.

As referred by Cortesão in a psychotherapy group, the members try to share feelings, conflicts, or convictions, designating these communication levels by levels of experience.

These experience levels are processed through the various forms of verbal and nonverbal communication which are always present and active in the group and it is with these levels that one globally intervenes in group psychotherapy. The analytical work regarding these experience levels in the group makes it possible to clarify them so that they acquire meanings which will enhance analysis and the therapeutic effect. Whether the conflict dimension arise more in the intrapsychic plan or in the interpersonal one, in both situations it becomes possible to transform experiences that emerge in the group in more differentiated modules of verbal communication. 
Cortesão (1989) mentions three levels of experience that emerge in the group: The level of individual subjective experience, when, for example, one element of the group describes an event or experience he/she lived in the present or in the past, or even the manifest content in a dream; the level of plural subjective experience when in a chain of thoughts other members of the group also speak about their own experiences, and the level of associative communication when one or more elements of the group comment what the others have said, by questioning or, for example, providing suggestions or information.

Interpretation is the technique which permits to translate into new and more differentiated forms of communication and psychological organization the various aspects of what is communicated in the group. Cortesão (1989) mentions that the term "interpret" integrates two dynamic meanings and two structures: It is active when it introduces more differentiated new meanings regarding the former communication and it is passive when the receptor gives a meaning to the interpretation which does not alter the former proposition or when the receptor doesn't understand it immediately, or even when the former proposition is not understood in its own context but will give rise to various thoughts and affections in the individual.

Regarding the interpretation levels in the analytic group, Cortesão (1989) mentions six levels. These are the genetic-evolutive, desenvolutive, signification, creativity, transference, and commutative levels.

The genetic-evolutive level of interpretation takes place when the interpretation accentuates the origins of the personality, investigating the structure, growth, and function of the Self. The desenvolutive level of interpretation occurs when one tries to correlate the different phases of development; the Self's inter-relation with the familiar and social matrixes and the way the Self reacts to change, frustration, and conflicts. According to Cortesão (1989), the genetic-evolutive level correlates more with causality and the desenvolutive interpretation level with possibilities of significance and creativity. The significance and creativity interpretation levels may occur when in certain circumstances of the analytical session, new meanings are given to what is described, and these same meanings may give rise to a different and innovating comprehension.

The "transference" and "commutative" interpretation levels are typical of group analysis, whilst in group analytic psychotherapy, the interpretation extends out to the creativity level.

In the context pertaining to these levels, the interpretation may be directed in various ways. It may be directed towards the group as a whole; towards one of the group's elements; towards certain relational aspects of the group analytical matrix; from one element of the group to another, and many other possibilities.

The group orientated interpretation or the interpretation towards an element of the group will reverberate in each element of the group in a unique way, according to his/her regression and fixation level at that given time. The objective of the interpretation is to broaden and to expand the mind of each member of the group, allowing simultaneously a larger elaboration of the Self.

\section{Working Through}

The term "working through" may be understood as a designation for individual work, a task performed by the individual, which may include suffering, pain, fatigue, pleasure, and a careful mental dedicated occupation.

In the context of group analysis and psychoanalysis, the concept does not differ greatly from the previous definition, but rather frames it in a psychic context with all the corresponding theory. In psychoanalysis vocabulary (Laplanche \& Pontalis, 1967), working through emerges as an analytical process in which interpretation is integrated, leading to the suppression of previously existing resistances in relation to 
interpretation of a thought or conduct. Thus, what is repressed begins to surface along with unconscious defence mechanisms, awareness of such repression and the subsequent reduction of the mechanisms leading to repetition. Although we are dealing with a process, or a way of psychically functioning, a constant in group analysis/psychoanalysis, it is intensified when the patient comes across as being stagnant, with no apparent evolution, due to the fact that resistance to the surfacing of repression is still present and no interpretation is incorporated or mentalized. The group analyst and/or the group members may interpret what is going on in this invisible working through moment, which, within the several contexts in which behaviour is repeated, will help to attenuate the defences and consequent emergence of repressed material.

Freud gives particular attention to the patient's resistances, to the way he/she gains awareness of them and may relate them to past situations and experiences. For Freud, acting out and the repetition of behaviour are the characteristics of repression. In transference with the analyst, the patient somehow repeats his behavioural patterns and his resistances emerge. Freud (1914) exemplifies: "The patient does not say that he remembers being challenging and critical in the past towards parental authority, but rather behaves in such a way with the doctor" (Vol. XII, p. 165). At the moment of repetition and acting out, the analyst draws attention to this situation, interprets it at that very moment and the repressed material, expressed through the symptoms, is able to emerge, to be mentalized, re-organised and, to a certain extent, re-stored. As Freud (1914) points out: "An absent or unreachable enemy cannot be thwarted" (Vol. XII, p. 168).

For Cortesão (1989), working through is an aspect of the group analytical process and takes place at a slow but continuous rate. Constancy and time are the aspects that have the greatest impact on the working through process. Cortesão (1989) quotes Glover (1958) when the latter refers to the slowness of the working through process, which highlights the fact that the factors determining this process also act gradually. For this author, these factors are: "(a) gradual psychic security; (b) new gradual introjections; (c) split projections, conceded by the Ego; (d) gradual expansion of the range of displacements, gradually leading to new adaptations; (e) gradual progression of libido and aggressive impulse functions; and (f) persistent labouring with the repetition compulsion". Working through is merely one of the aspects of analytical work.

\section{The Mirror Phenomenon}

Foulkes (1957) described the mirror phenomenon as a fundamental aspect of the group-analytic phenomenology and one of the basis of this therapy, according to which the different group members though their interaction reveal the different aspects that characterize each one of them. According to him, it contributes for the organization of the group-analytic matrix itself (described as network of relationships, communication and transference, in which the group-analytic process occurs) and for the development of the Ego training in action (analysis of the relationships in interaction of the different structures-Ego, Super-Ego, and Id - of the different group members), entity that constitutes for him the basis of the group-analytic therapy.

Leal (1968) gave also a fundamental importance to this phenomenon in the organization of the internal relational matrix that Foulkes (1968) preferred to call the group personal matrix, conception that we think to be one of the fundamental basis of the group analytic process, and the establishment and working though of the group transference neurosis. To explain them, she based also her point of view on Watson (1967) and Lorenz (1963) behavior conceptions and Bowlby $(1969 ; 1973)$ ethologic points of view.

In psychoanalysis, the mirror phenomenon is linked to the state of primary narcissism and was described for the first time, in this context, by Jacques Lacan (1966). 
Kohut (1984) thinks that or on the contrary, this phenomenon is linked to the two states that succeed to the last one referred, and that are the grandiose self and the idealized parental imago. Simultaneously he speaks of a normal narcissism that he opposes to the pathological one, centered on the investment of libido on the Ego. In this context, the interactions that occur between the group members are expressed through object relations, that in this case are external, and that are, necessarily, linked to the mirror phenomenon.

On the contrary, the point of view of the object relations theory, particularly of the English middle group, is that the internal object relations are expressed and modified through their external dimensions.

Cortesão (1981) did not seem to be very far from this point of view, when he considered the mirror phenomenon to be, contrarily to Foulkes' $(1957$; 1964; 1965) point of view, explained by an ensemble of defense mechanisms: splitting/introjection/projection/projective identification.

In any case, according to our point of view (Ferreira, 2004), this conception (as any other that will take place in this framework) should be done in the context of the group-analytic metatheory and, particularly, in interaction with its fundamental conceptions (as those of pattern, matrix, internal relations matrix are).

\section{Resonance}

In 1991, Lionel Kreeger, founding member of the Institute of Group Analysis of London, defined resonance as "The phenomenon of intensification or amplification of a particular theme or conflict within the group, resulting from shared, largely unconscious communication between its members". This author is taking what Foulkes and Anthony had already established, starting in the 1950s, in "Group Psychotherapy—The Psychoanalytic Approach". The phenomenon of "resonance" is another analogical term derived from the physical sciences. The genetic theory of psychoanalysis supposes in every normal individual an orderly development through certain "psycho-sexual" stages, and explains that this process may be disturbed by interferences that may lead the individual to one of three situations - to become "fixated" on a certain stage (the one in which the interference happened); or regress to a previous stage of development; or show "evidence of precocity". When this person joins a therapeutic group, they meet other people who are on different levels of the "psycho-sexual scale". Each of these people will react to any occurrence within the group according to their own level. The deep, unconscious "frame of reference" is laid down in the first five years of life and predetermines associative responses from then on. According to Foulkes (1975), this is very evident in the group situation. He writes of various examples of what is here defined as resonance, talking about the group, and mentions an unconscious intercommunication mechanism. This author sees the group as a totality; he describes it as a gestalt, in which all the elements and the whole must be considered simultaneously. He also draws attention to what he names the "holistic danger", which consists in a tendency to consider the group as if it were an individual. In group analysis, we consider the contribution of different members as they follow upon each other as having an associative connection (group association). There is frequently an element of unconscious interpretation involved. This element is somehow always present, with the communication that happens within the group being understood in different levels - with interpretations that can be conscious or unconscious. Each individual picks out, as it were, from a common pool which is the most meaningful to him personally. This is comprehended in the phenomena he calls resonance. The differentiation of levels is based not only on the different "psycho-sexual development levels" but also on the different reactive formations and defense mechanisms with which the ego deals with conflictual material. 
And so, the concept of resonance seems to us to be inseparable from the notions of "network" and "group matrix"; and more, we would go as far as to say that resonance is inexorably linked to the creation of the network and the group matrix, and of an underlying condition to the other communication phenomena present in the group.

Ezriel (1950) specified resonance as "phantasmatic resonance"- the phantom of one element awakens and mobilizes other phantasmatic formations in other members of the group, in resonance with the first. Due to this phenomenon, the group finds itself in a position to transfer, through the action of this fantasy, to the analyst, who will then take the productions of the participants as he would have taken the material of an individual patient. As Marcos Bernard (2006) explains, fantasy, as we can see, is shared: Different members of a group can share a fantasy activity in a certain way and play the roles of certain characters or elements in this fantasy — and this is what gives each group its own characteristics.

\section{Free Floating Discussion}

What happens in a group analytic group?

What do their members do?

The answer is: They communicate, of course.

Each one communicates with the others and with the group analyst their feelings, fears, phantasies, anxieties and anything we might conceive that a human being could feel.

There is not a specific issue to communicate; each one talks to the others about whatever they want, according to their current concerns.

The members of the group are encouraged to talk spontaneously and to communicate whatever crosses their minds, without avoiding any thought or theme that could arise.

This kind of communication is the group analytic equivalent to the Freud's (1900) well-known concept of "free association of ideas" and was named by Foulkes (1964), the pioneer of group analysis, as "free floating discussion".

Its purpose is, as well as in psychoanalysis, to facilitate the emergency of the primary process of thought and, consequently, unconscious contents such as conflicts and phantasies that could be used in a therapeutic way.

The group analyst and the other members of the group try to understand all the communications, giving them a new meaning which could be shared and could make sense.

\section{The Anti-Group}

The anti-group is a broad term that includes the whole of the aggressive and destructive phenomena that may occur in a group. These may be either latent or manifest through several forms.

Aggression and destructivity are rather well known and recognized from the beginning of group analysis, appearing as repeated absences, delays, acting outs, drop-outs, scapegoating, malignant mirroring, and verbal violence. Nevertheless, they hadn't been enough valued until they were introduced by Morris Nitsun in 1996 as the anti-group.

"The anti-group is a broad term describing the destructive aspect of groups that threatens the integrity of the group and its therapeutic development..."

"...I also believe that the successful handling of the anti-group represents a turning point in the development of the group, as well as of each member, I would say" (Neto, 1999). 
"The anti-group is not conceived as a monolithic force that inevitably destroys the group. Rather, it is seen in a complementary relationship with creative group processes, but requiring recognition and handling in order that the constructive development of the group can proceed without serious obstruction. The conflict between creative and destructive is itself seen as generative: It heightens and illuminates the paradoxical nature not only of the group but of human life in general and its containment and recognition is strengthening".

Concerning causality, we may find mainly the transference through splitting, displacements, projections, and projective identifications. The other becomes the deposit of the rejected negative parts of the selves and/or their primary internalized objects. The other lose their independence and individuality, becoming the enemy to be destroyed or from whom one must run away.

The above transference relational phenomena rooted in the past primitive object relationships may be triggered by several causes, more or less determined either by the reality of each member and/or by the group as a whole. Among these we consider the sibling rivalry that haven't been enough conceptualized by psychoanalysts (Mitchell, 2003) and by group analysts who have included it inside the Oedipus complex. Sibling rivalry is deeply dependent on the way parents deal with the group of their children as well as with the ubiquitarious need of the human baby to be the unique and unconditionally loved by the primary care givers. Therefore, beyond similarities, there are differences between Oedipus and sibling rivalries.

Sibling rivalry appears in a quick and clear way in groups. This way, we consider groups as a very important setting to understand and work through these kinds of conflicts. Nevertheless, we must not devaluate the difficulties that this work implies. The entrance of a new element in the group is one of the trigger situations of this kind of conflicts which may enhance high levels of aggression based mainly on jealousy and envy. These are painful situations that may be analysed and overcome with healthy consequences on other areas of ones' lives: familiar (husbands, wives, children), and professional. This way, chronic dysfunctional relational patterns may be stopped or, at least, ameliorated.

Thus, we may say that one of the added values of group analysis is the diagnosis, understanding, and potential resolution of misunderstandings. We think that was David Zimerman, a brasilian psychoanalyst and group analyst who defined psychoanalysis as the science that studies misunderstandings.

The whole of the interactions and relationships established inside a group analytic group include also mirror phenomenon more or less realistic. Mirroring may become extremely distorted because of transference and primitive defence mechanisms, leading to a potential huge destructivity. The concept we are referring to is the one that Louis Zinkin called Malignant Mirroring in 1983. Malignant Mirroring is much frequent among human beings and is responsible for multiple destructive behaviours in many circumstances. If we are dealing with a group analytic group, it may be possible that this destructiveness may be understood, transformed and, thus, overcome.

\section{Conclusion}

(1) We must take into account that every group contains in itself an aggressive potential that shall be neither devaluated nor denied as well as shall not be stimulated on purpose. Aggression will appear spontaneously, reactively to triggers being more or less predictable;

(2) Concerning the triggers, there are those more predictable which may occur in every group. Interruption of the sessions, mainly due to the group analyst/conductor, discharges, drop-outs and new comers are among this group of triggers; 
(3) There are other kind of triggers more difficult to be anticipated which are more dependent on the mental organization of each member including the GA/conductor. Among these, we highlight empathic injuries and failures which are usually a common and frequent cause of frustration and aggression. This aspect will be felt as more violent if the empathic failure is perpetrated by the GA/conductor;

(4) We must identify the destructive phenomena in a group as soon as they become explicit in a more or less clear way;

(5) We must understand the anti-group in the context of the group's evolution, each member's mental organization and life history, transference and counter transference;

(6) Afterwards, we must work on the several meanings of the destructive behaviours, name them, that is, it's time to interpret;

(7) Aggression must not be neither avoided nor denied. It must be understood so that it may be transformed, deprived of the displaced transference mechanisms into more realistic and creative attitudes towards oneselve and others. This process was part of what Cortesão (1991) called the "aesthetic equilibrium".

\section{References}

Ancona, L. (1992). Matrix et Pattern en analyse de groupe ou grupanalse. Grupanálise, 4, 39-45.

Bernard, M. (2006). El trabajo psicoanalítico con pequeños grupos. Buenos Aires, Argentina: Lugar Editorial.

Bowlby, J. (1969). Attachment and loss. New York, NY: Basic Books.

Bowlby, J. (1973). Separation: Anxiety and anger. London, United Kingdom: Hogarth.

Campbell, R. J. (1983). Comprehensive group psychotherapy (H. I. Kaplan Ed., 2nd ed.). New York.

Cortesão, E. L. (1981). Experiência clínica no tratamento de estados neuróticos psicóticos com grupanálise e psicoterapia grupanalítica-Contribuição para uma teoria da técnica (Dissertação para as provas de agregação, Faculdade de Ciências Médicas de Lisboa, Lisbon, Portugal).

Cortesão, E. L. (1989). Grupanálise: Teoria e técnica. Lisbon, Portugal: Fundação Calouste Gulbenkian.

Cortesão, E. L. (1991). Group analysis and aesthetic equilibrium. Group Analysis, 24(3), 271-77.

Dinis, C. V. (1994). Algumas reflexões a propósito da neurose de transferência em grupanálise. Grupanálise, 5, 7-18.

Dinis, C. V. (2001). Existir na net e ser na matriz grupanalítica. Revista Portuguesa de Grupanálise, 3, 15-26.

Ezriel, H. (1950). A psycho-analytic approach to group treatment. British Journal of Medical Psychology, 23(1, 2). Doi: 10.1111/j.2044-8341.1950.tb00371.x

Ferreira, A. G. (2004). O problema e a procura duma metateoria em grupanálise. Revista Portuguesa de Grupanalise, 17-30.

Foulkes, S. H., \& Anthony, E. J. (1957). Group psychotherapy-The psychoanalytic approach. London, United Kingdom: Penguin Books Ltd..

Foulkes, S. H. (1962). Therapeutic group analysis. London, United Kingdom: Karnac.

Foulkes, S. H. (1964). Therapeutic group analysis. London, United Kingdom: George Allen \& Unwin.

Foulkes, S. H. (1965). Group analytic psychotherapy: Methods and principles. London, United Kingdom: Gordon and Breach.

Foulkes, S. H. (1968a). Coments on Dra. Leal's contributions. GAIPAC, I (2), páginas.

Foulkes, S. H. (1968b). Coments on Dra. Leal's contributions. GAIPAC, IV(1).

Foulkes, S. H., \& Anthony, E. J. (1973). Group -Psychotherapy-The psychoanalytic approach. Penguin Books. UK.

Foulkes, S. H. (1975). Group analytic psychotherapy_Method and principles. London, United Kingdom: Gordon \& Breach Science Publishers Ldt..

Foulkes, S. H. (1977). Group—Analytic therapy—Method and principles. London, United Kingdom: Gordon and Breach Science Publishers.

Freud, S. (1900). Interpretation of dreams (Standard Edition, IV \& V). London, United Kingdom: Hogarth Press.

Freud, S. (1914). Recordar, repetir e elaborar (novas recomendações sobre a técnica da psicanálise II). In J. Strachey (Ed.), Edição standard brasileira das obras psicológicas completas de Sigmund Freud (Vol. XII). Rio de Janeiro, Brasil: Imago Editora. 
Hopper, E. (2006). Theoretical and conceptual notes concerning transference and countertransference processes in groups and by groups and the social unconscious: Part 1. Group Analysis, 39(4), 549-559.

Kadis, A., Krasner, J., Winick, C., \& Foulkes, S. (1963). A practicum of group psychotherapy. New York, N.Y.: Harper and Row.

Kohut, H. (1984). How does analysis cure? The self-object transferences and interpretation. Chicago, I.L.: University of Chicago Press.

Kreeger, L. (1991). In J. Roberts \& M. Pines (Eds.), The practice of group analysis. London, United Kingdom: Tavistock/Routledge.

Kutter, P. (1976). Basic aspects of psychoanalytic group therapy. London, United Kingdom: Routledge \& Kegan.

Lacan, J . (1966). Écrits. Paris, France: Seuil.

Laplanche, J., \& Pontalis, J. B. (1967). Vocabulário de psicanálise. Lisboa, Portugal: Moraes Editores.

Leal, M. R. (1968). Grupanálise-Um percurso 1963-1993. Lisboa, Portugal: Edições Sociedade Portuguesa de Grupanálise.

Leal, M. R. (1970). Le Transfert analytic dans l'analyse de groupe. Bulletin de Psychologie de l'Université de Paris, 285, XXIII, (13-16), 760-764.

Leal, M. R. (1990). Porque resulta a grupanálise? Grupanálise, 2, 41-54.

Lorenz, K. (1963). On aggression. London, United Kingdom: Methuen Paperback.

Mello Filho, J. (1986). Contribuições da escola de winnicott à psicoterapia de grupo. Porto Alegre, Brasil: Artes Médicas.

Mitchell, J. (2003). Siblings, sex and violence. Cambridge, United Kingdom: Polity Press.

Neto, I. M. (2003) Estabelecendo elos entre a realidade interna e a realidade externa: Os membros do grupo como encenação da realidade interna do analista. Grupanaliseonline, 1(1), 24-28. Retrieved from http://www.grupanalise.pt/images/stories/revist aonline/pdfs/revistaonline1.pdf

Neto, I. M. (1999, May 28-30). The freedom and the capacity to say no and its healing potential. Paper presented at the EFPP II European Conference on Group Analytic Psychotherapy. Barcelona, Spain.

Nitsun, M. (1996). The anti-group: Destructive forces in the group and their creative potential. London: United Kingdom: Routledge.

Rouchy, J. C. (1982). Archaic processes and transference in group analysis. Group Analysis, 15, 235-260.

Rycroft, C. (1968). A critical dictionary of psychoanalysis. London, United Kingdom: Penguin Books.

Stern, D. N., Sander, L. W., Nahum, J. P., Harrison, A. M., Lyons-Ruth, K., Morgan, A. C., Bruschweiler-Stern, N., \& Tronick, E. Z. (1998). Non interpretative mechanisms in psychoanalytic therapy: The "something more" than interpretation, the process of change study group. International Journal of Psychoanalysis, 79, 903-921.

Watson, J. (1967). Memory and contingency analysis in infant learnin. Merril-Parma Quarterly, 13, 55-76.

Watson, J. (1972). Smiling, cooing and the game. Merril-Parma Quarterly, 18, 323-339.

Zimerman, D. (2005). As transformações na minha forma pessoal de praticar grupanálise ao longo de uma experiência de mais de 40 anos. Revista Portuguesa de Grupanálise, 17-31.

Zinkin, L. (1983). Malignant mirroring. Group Analysis, 16, 113-126. 